\title{
Equilibrium, Thermodynamic and Kinetic studies for biosorption of Terasil Brown 2RFL from contaminated water using economical biomaterial
}

\author{
Haq Nawaz Bhatti", Saima Noreen, Noor Tahir, Sadia Ilyas and Umme Habibah Siddiqua \\ Environmental and Material Chemistry Laboratory, Department of Chemistry, University of Agriculture, \\ Faisalabad-Pakistan
}

\begin{abstract}
The present study investigated the potential of native and modified sugarcane bagasse for the biosorption of Terasil Brown 2RFL from wastewater. The novelty of present work is the preparation of cost effective, efficient and ecofriendly biosorbent for the removal of disperse dye using waste sugarcane bagasse after different simple and inexpensive physical and chemical treatments. The optimization of various physicochemical factors like $\mathrm{pH}$, biosorbent dose, contact time, initial dye concentration and temperature was carried out in batch mode. It was observed that the biosorption capacity of native, CTAB treated and immobilized biosorbent was decreased from 54.78 to $34,60.56$ to 39.1 and 27.34 to $18.65 \mathrm{mg} / \mathrm{g}$ by decreasing $\mathrm{pH}$ from 2 to 9 . The optimum $\mathrm{pH}$ was found to be 2. The reduction in biosorption of disperse dye from 75.4 to $12,87.59$ to 23.44 and 35.66 to $10.78 \mathrm{mg} / \mathrm{g}$ was found for native, pretreated and immobilized biosorbent by increasing the dose of biosorbent from 0.05 to $0.3 \mathrm{~g}$. Kinetic study showed the increase of dye removal by increasing the time from 5 to $90 \mathrm{~min}$ for native, CTAB treated and immobilized sugarcane bagasse respectively and there was not any effect on removal was observed after $90 \mathrm{~min}$. At $90 \mathrm{~min}$, the obtained biosorption capacities were 78.99, 89.22 and $38.99 \mathrm{mg} / \mathrm{g}$ for native, pretreated and immobilized biosorbent respectively. From the equilibrium study, it was found that the biosorption capacity was increased from 13.88 to $85.67,20.88$ to 94.65 and 10 to $56.77 \mathrm{mg} / \mathrm{g}$ by increasing the initial dye concentration from 10 to $100 \mathrm{mg} / \mathrm{L}$. Thermodynamic study revealed the reduction in biosorption capacity from 76.55 to $49,89.87$ to 60 and 35 to $15 \mathrm{mg} / \mathrm{g}$ by increasing the temperature from 30 to $60{ }^{\circ} \mathrm{C}$. The $0.05 \mathrm{~g}, 90 \mathrm{~min}, 100 \mathrm{mg} / \mathrm{L}$ and $30{ }^{\circ} \mathrm{C}$ were observed as optimum environmental conditions to attain the maximum removal of disperse dye from contaminated water using native, pretreated and immobilized sugarcane bagasse. The well fitted equilibrium and kinetic models were found to be Langmuir and pseudo-second-order. Thermodynamic study showed the spontaneous and exothermic nature of biosorption process. It was estimated that the CTAB treated sugarcane bagasse could be used as an efficient, environment friendly and cost effective biosorbent for the removal of Terasil Brown 2RFL from aqueous solution.
\end{abstract}

Keywords: Biosorption; Removal; Disperse dye; Equilibrium; Kinetics.

\section{Introduction}

Modern society has major problem of aquatic pollution due to industrial activities ${ }^{1}$. Different industries like textile, cosmetic, pulp mill, pharmaceutical and leather have been played key role in causing water pollution by discharging huge volume of wastewater which contained large quantity of untreated organic and inorganic pollutants ${ }^{2}$. Especially, textile industries have been used lot of water during wet processes and as result released colored wastewater in large volume ${ }^{3}$. Color is considered to be important high rated hazardous pollutant among wastewater organic pollutants which require being removed ${ }^{4}$. These dyes are produced lethal effects on humans like nausea, allergy, cancer, mutation and skin irritation as well as affected the aquatic life because these are formed layer on the surface of water which reduce the penetration of light and inhibit the process of photosynthesis ${ }^{5}$. It also caused the micro toxicity in fish through complex formation with heavy metals. Additionally, these are also caused visual pollution and destroyed the beauty of natural water bodies. The undesired quantity of dye in textile wastewater depends on type of dye which is applied ${ }^{6}$.

Among the dyes which are mostly utilized in textile industries in world are azo dyes. These include acidic, basic, direct, reactive, vat and disperse dyes etc. In disperse dyes; the azo chromophores are attached with aromatic moieties ${ }^{7}$. These dyes are formed the colloidal dispersion and having low solubility in water and can be used to 
color the different synthetic fibers like nylon, cellulose and polyester etc ${ }^{8}$.

The dyes present in industrial wastewater showed difficulty in degradation through conventional technologies because of having complex and stable molecular structure. Their structure showed stability towards light, microbial attack and temperature ${ }^{9}$.

Several physical and chemical methods have been developed for the treatment of contaminated water like adsorption, coagulation, chemical oxidation, Fenton reaction, reverse osmosis, flocculation and membrane processes etc. All these methods except adsorption have some limitations with respect to cost, sludge production, chemicals usage and less effectiveness. Biological treatments also have drawback because aerobic and anaerobic conditions are required ${ }^{10}$.

Adsorption is considered to be simple, effective and cheap technology as compared to other physical and chemical methods ${ }^{11}$. Biosorption technology is used to remove the organic and inorganic pollutants from aqueous solution using inactive biomass ${ }^{12}$. Firstly, attention has been given in utilization of activated carbon for removal of dye but it also has drawback due to have high cost for its activeness. Recently, lot of research has been carried out for the search of an efficient and economical biosorbent. Nowadays, the use of different agricultural wastes like bamboo waste, coconut shell, peanut, rice husk, corn cobs and wheat bran etc as biosorbent has attained very attention because of ease of availability, local abundance, cheapness, high efficiency and less treatment need before usage ${ }^{13}$.

The aim of present study was to evaluate the potential of native, pretreated and immobilized sugarcane bagasse for disperse dye from aqueous solution. The effect of various environment factors like $\mathrm{pH}$, biosorbent dose, contact time, initial dye concentration and temperature on biosorption capacity was estimated. Different equilibrium, kinetic and thermodynamic parameters for the removal of disperse dye from contaminated solution were also determined. The effect of ionic strength, heavy metal ions and surfactants was also observed on elimination of disperse dye. The biosorption process was made cost effective by doing desorption study.

\section{Materials and Methods}

\section{Selection and preparation of biosorbents}

For the elimination of disperse dye from aqueous solution, the biosorption capacity of different agricultural wastes was investigated. For present study, peanut hull, sunflower waste, corn cobs, cotton sticks and sugarcane bagasse was selected and all these were collected from local markets.

All these biosorbents were made clean from dust by given washing with tap water and then oven dried at $60{ }^{0} \mathrm{C}$ for 24 hours. After drying them, all these biosorbents were crushed and grinded and then collected after sieving through octagon siever (OCTDIGITAL 4527-Ol) of $0.250 \mathrm{~mm}$ particle size. All these sieved biosorbents were saved in tight plastic bottles for further study. Sugarcane bagasse was screened among all these collected biosorbents because it gave good biosorption capacity for disperse dye.

\section{Pretreatment of biosorbent}

The screened biosorbent was given different physical and chemical treatments for investigating improvement in its biosorption capacity for disperse dye. Boiling and heating was carried out as physical treatment while the screened biosorbent was shaked with 5 percent solution of acids, alkalis, surfactants, organic solvents and different chelating agents for 1 hour at $120 \mathrm{rpm}$ and $30{ }^{\circ} \mathrm{C}$ in chemical treatment. The screened biosorbent was treated with $\mathrm{HCl}$, $\mathrm{CH}_{3} \mathrm{COOH}, \mathrm{H}_{2} \mathrm{SO}_{4}$ and $\mathrm{HNO}_{3}$ in acid treatment and $\mathrm{KOH}, \mathrm{NaOH}, \mathrm{NH}_{4} \mathrm{OH}$ was used for modifying screened biosorbent in alkalis treatment. Different types of surfactants, anionic SDS, cationic CTAB and non ionic Triton-X 100 was utilized for modification. Different chelating agents PEI, glutaraldehyde, EDTA and organic solvents like $\mathrm{CH}_{3} \mathrm{OH}, \mathrm{C}_{6} \mathrm{H}_{6}$ were used in chemical treatment. After shaking, all these modified biosorbents were collected by filtration and then 2 to 3 times washed with distilled water. After washing, all these were dried in oven at $60{ }^{\circ} \mathrm{C}$ for 24 hours and then saved for further utilization ${ }^{14}$.

\section{Immobilization of biosorbent}

Native biosorbent consist of little particles having less density, mechanical strength and rigidity due to that reason different problems are produced in solid - liquid separation like swelling of biomass and inability to regeneration. Sodium alginate beads of screened biosorbent were prepared for the comparison among the native, pretreated and immobilized biosorbent. For that purpose first made the aqueous slurry of native screened biosorbent with sodium alginate in 1: 2 ratios on mass percent basis. Then took burette $(100 \mathrm{~mL})$ and put slurry into that burette and added drop wise in the $0.10 \mathrm{M} \mathrm{CaCl}_{2}$ solution. When slurry entered into solution it adopted the shape of beads. These beads were washed with distilled water and stored in $0.01 \mathrm{M}$ $\mathrm{CaCl}_{2}$ solution ${ }^{15}$.

\section{Preparation of stock solution of dye}

The disperse dye Terasil Brown 2RFLwas obtained from commercial market of Faisalabad city, Pakistan. For stock solution preparation, firstly weighed the $1 \mathrm{~g}$ of dye keenly on analytical balance and then dissolved in few $\mathrm{mL}$ of distilled water in $1000 \mathrm{~mL}$ measuring flask and then made the volume up to $1000 \mathrm{~mL}$. After preparation, the stock solution was saved in air tight glass bottle for further used. Different dilutions that required were made from that stock solution easily. 


\section{Batch sorption study}

The batch biosorption study was carried out for optimizing different process parameters like $\mathrm{pH}$ (29), biosorbent dose $(0.05-0.30 \mathrm{~g})$, initial dye concentration (10-200 mg/L), contact time (5-120 min) and temperature $\left(30-60{ }^{\circ} \mathrm{C}\right)$ for the biosorption of Terasil Brown 2RFLby using different forms of sugarcane bagasse (Native, CTAB treated and Immobilized). Each batch biosorption experiment was run in $250 \mathrm{~mL}$ Erlenmeyer flasks contained $50 \mathrm{~mL}$ of certain dye concentration solution and biosorbent dose at constant $\mathrm{pH}$ and temperature by shaking in orbital shaker at $120 \mathrm{rpm}$. After shaking, the supernatant was collected by centrifugation and then analyzed the dye anions concentration by using UV-Vis spectrophotometer (Shimadzu Brand UV-4000). Each experiment was performed in duplicate and the average results were used for making calculations. The biosorption capacity was estimated by using the following equation:

$$
q_{e}=\frac{\left(C_{o}-C_{e}\right) V}{W}
$$

Where $\mathrm{q}_{\mathrm{e}}$ is the biosorption capacity $(\mathrm{mg} / \mathrm{g})$ of biosorbent for dye while the $\mathrm{C}_{\mathrm{o}}$ and $\mathrm{C}_{\mathrm{e}}$ is the initial and equilibrium concentrations of dye $(\mathrm{mg} / \mathrm{L})$ respectively. $\mathrm{V}$ is the dye solution volume $(\mathrm{L})$ and $\mathrm{W}$ $(\mathrm{g})$ is the biosorbent dry weight ${ }^{16}$.

\section{Results and Discussion}

The removal of Terasil Brown 2RFL from aqueous solution was carried out in batch mode using native, CTAB treated and immobilized sugarcane bagasse. The fitness of experimental data was checked by applying different equilibrium and kinetic models. Different thermodynamic parameters were also calculated.

\section{Effect of Screening}

Screening of best biosorbent among different agricultural wastes like peanut hull, sugarcane bagasse, corn cob, cotton stick and sunflower waste was done at constant environmental conditions such as $\mathrm{pH}=3$, biosorbent dose $=0.1 \mathrm{~g}$, contact time $=90$ min, temperature $=30^{\circ} \mathrm{C}$ and shaking speed $=120 \mathrm{rpm}$. It was found that the sugarcane bagasse showed the maximum biosorption capacity for disperse dye as compared to other used agricultural wastes. The results are shown in Fig.1 and Table 1. Therefore, sugarcane bagasse was selected as best biosorbent for further study ${ }^{17}$.

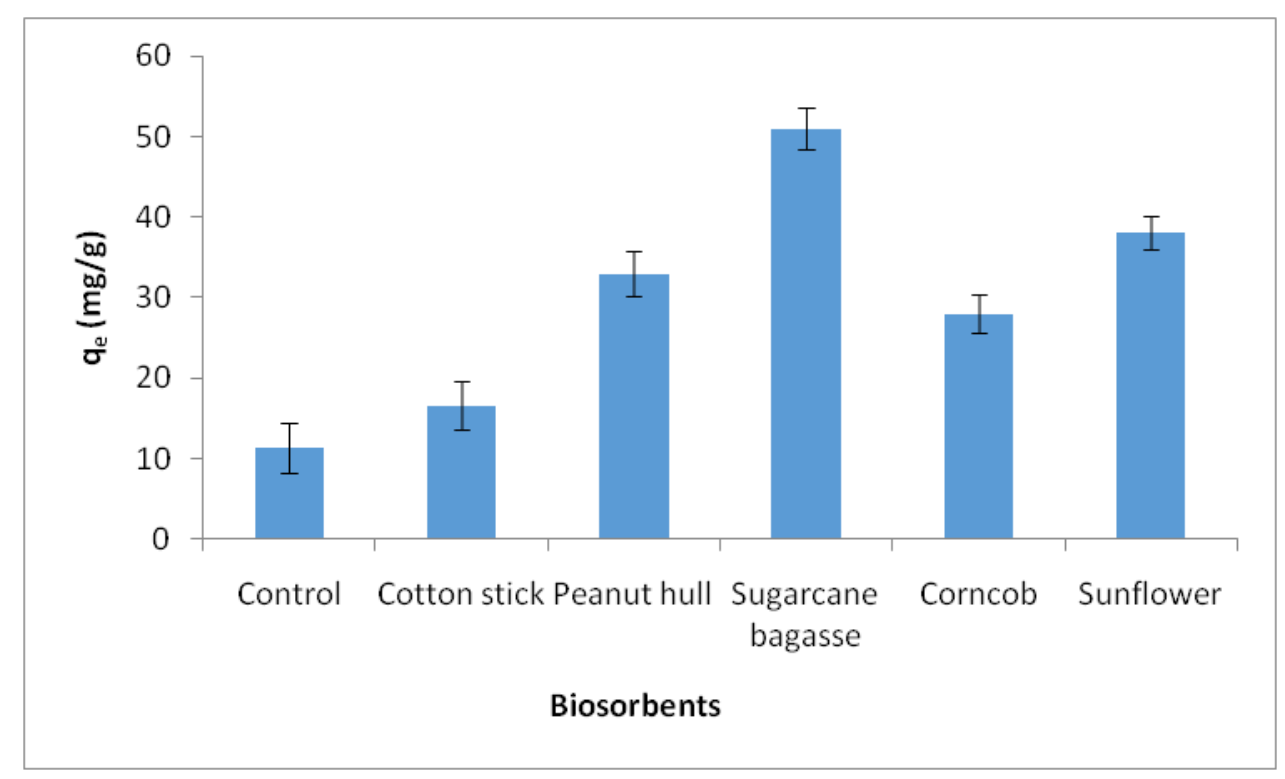

Figure 1. Screening study of Terasil Brown 2RFL with different biosorbents

Table 1. Comparison of biosorbents for biosorption of Terasil Brown 2RFL.

\begin{tabular}{|l|l|l|l|l|l|}
\hline Biosorbent & Cotton stick & Peanut hull & Sugarcane bagasse & Corncob & Sunflower \\
\hline $\mathbf{q}_{\mathbf{e}}(\mathbf{m g} / \mathbf{g})$ & 16.64 & 33 & 51 & 28 & 38 \\
\hline
\end{tabular}




\section{Effect of treatments}

Different physical and chemical treatments were given the selected biosorbent to improve its biosorption capacity for disperse dye. The effect of these treatments were checked, either the biosorption capacity was increased or decreased by doing these treatments. The results are shown in Fig. 2. It was observed that some of treatments increased the attraction of sugarcane bagasse for disperse dye and some of treatments reduced its efficiency as compared to native biosorbent. The following descending order represented the effect of treatments on biosorption capacity of sugarcane bagasse for Terasil Brown 2RFL. $\mathrm{CTAB}>\mathrm{PEI}>\mathrm{HCl}>\mathrm{H}_{2} \mathrm{SO}_{4}>\mathrm{CH}_{3} \mathrm{COOH}>\mathrm{HNO}_{3}>$ autoclave $>$ Boiling $>$ Benzene $>$ Native $>\mathrm{NaOH}>\mathrm{KOH}>$ $\mathrm{NH}_{4} \mathrm{OH}>\mathrm{CH}_{3} \mathrm{OH}>$ Glutaraldehyde $>$ Triton $\mathrm{X}-100>$ SDS > EDTA. From results, it was examined that the biosorption capacity of biosorbent was enhanced by treating with cationic surfactant CTAB. CTAB might be created more positive charge on surface of sugarcane bagasse which increased the electrostatic interaction between surface functional groups and dye anions. The biosorption capacity was also improved with acids which might be due to the protonation of active functional groups on biosorbent surface $^{18}$. The PEI enhanced the attraction of sugarcane for Terasil Brown 2RFL by creating more amine groups on biomass surface which showed more attraction for dye anions ${ }^{19}$. The physical treatments such as autoclave, boiling and organic solvents like benzene also improved the biosorption capacity of sugarcane bagasse by removing lipids and minerals which masked the active binding sites $^{20}$. Alkaline modification reduced the biosorption capacity of sugarcane bagasse which might be the deprotonation of functional groups on surface of biomass which caused the repulsion of dye anions $^{14}$. The reduction in removal of disperse dye by methanol indicated the formation of ester on biosorbent surface due to reaction between surface carboxylate ions and methanol ${ }^{21}$. Glutaraldehyde modification created the cross linking between active surface functional groups which reduced the availability of functional groups for dye anions ${ }^{22}$. EDTA is chelating agent, its treatment with biosorbent decreased the active binding functional groups by chelating them. The anionic and nonionic surfactants like SDS and Triton X-100 also caused reduction in biosorption capacity due to creation of hindrance among dye anions and active binding sites.

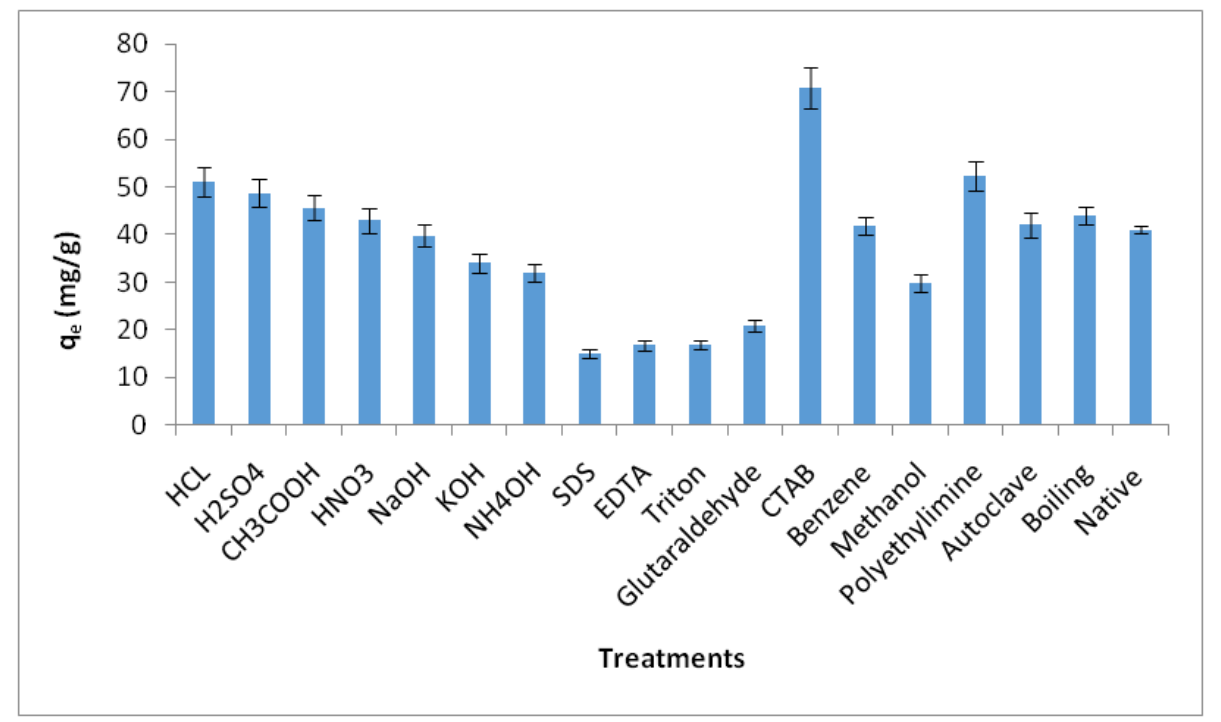

Figure 2. Effect of physical and chemical treatments on sugarcane bagasse

\section{Evaluation of Optimization Conditions Effect of pH}

Firstly, the effect of $\mathrm{pH}$ on biosorption capacity of native and modified sugarcane bagasse was determined because it is the important sensitive environmental factor which influences the biosorpton studies by changing the solubility and also color of dye solution. The effect of solution $\mathrm{pH}$ (2-9) was found out by conducting experiment at constant experimental conditions. The $50 \mathrm{~mL}$ and 50 $\mathrm{mg} / \mathrm{L}$ of disperse dye was continuous stirred at 120 $\mathrm{rpm}$ and $30{ }^{\circ} \mathrm{C}$ using $0.1 \mathrm{~g}$ of native, CTAB treated and immobilized sugarcane bagasse. The effect of $\mathrm{pH}$ is represented by Figure 3. The results depicted the reduction in biosorption capacity of native and modified forms by changing the $\mathrm{pH}$ from 2 to 9 . The maximal removal of disperse dye was achieved at lower $\mathrm{pH} 2$ for all forms of sugarcane bagasse. The lower acidic $\mathrm{pH} 2$ was found to be optimum due to give high biosorption capacities 54.78, 60.56 and $27.34 \mathrm{mg} / \mathrm{g}$ for native, CTAB treated and immobilized sugarcane bagasse respectively. It was observed that the $\mathrm{pH}$ lower than 2 could not determined because the change in solution color was observed due to structural change of dye. The biosorption capacity was reduced from 54.78 to 34 , 60.56 to 39.1 and 27.34 to 18.65 for native, CTAB treated and immobilized sugarcane bagasse by changing $\mathrm{pH}$ from 2 to 9 . Such trend might be due to deprotonation of surface functional groups at higher 
$\mathrm{pH}$ which reduced the electrostatic interaction between the dye anions and active binding sites ${ }^{5}$. The higher removal at $\mathrm{pH} 2$ might be because of protonation of surface functional groups which increased the attraction of biosorbent for dye anions. A similar effect of $\mathrm{pH}$ has been reported on the removal of disperse dye in batch study ${ }^{23}$.

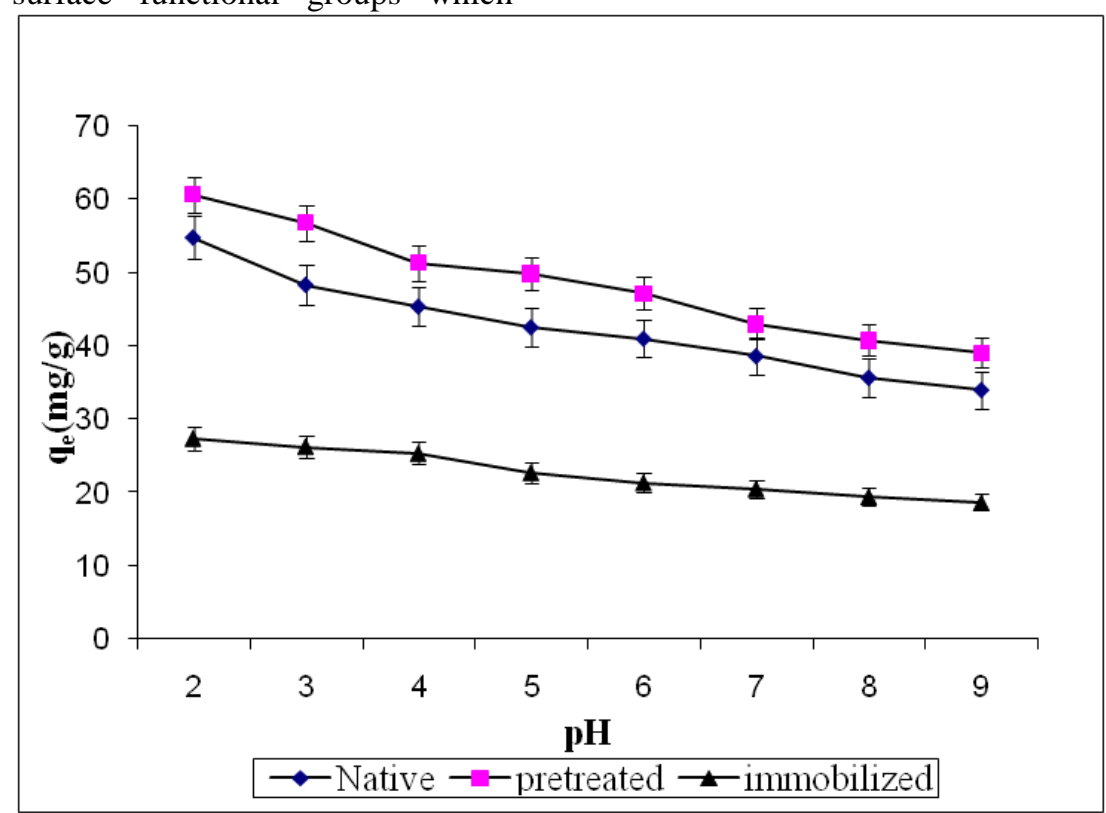

Figure 3. Effect of $\mathrm{pH}$ on biosorption of Terasil Brown 2RFL using native and modified sugarcane bagasse.

\section{Effect of biosorbent dose}

The estimation of biosorbent dose has significant importance for designing of an economical system for biosorption ${ }^{24}$. The effect of biosorbent dose (0.05-0.3 g) on biosorption of Terasil Brown 2RFL from aqueous solution using native and modified sugarcane bagasse at $2 \mathrm{pH}, 50 \mathrm{mg} / \mathrm{L}$ of initial dye concentration, $30^{\circ} \mathrm{C}$ temperature and $120 \mathrm{rpm}$ shaking speed was determined. The results are shown in Figure 4. From results, it was observed; $0.05 \mathrm{~g}$ of native, CTAB treated and immobilized sugarcane bagasse was considered as an optimum dose. The biosorption capacity of native, CTAB treated and immobilized sugarcane bagasse was decreased from 75.40 to $12.0,87.59$ to 23.44 and 35.66 to $10.78 \mathrm{mg} / \mathrm{g}$ by increasing the biosorbent dose from 0.05 to $0.3 \mathrm{~g}$. The reason might be the aggregation of biosorbent particles at high dose which caused formation of biosorbent layers, shortened the surface area and enhanced the path length of diffusion ${ }^{25}$. A similar effect of biosorbent dose on the removal of Foron blue dye has been reported with sugarcane bagasse ${ }^{26}$.

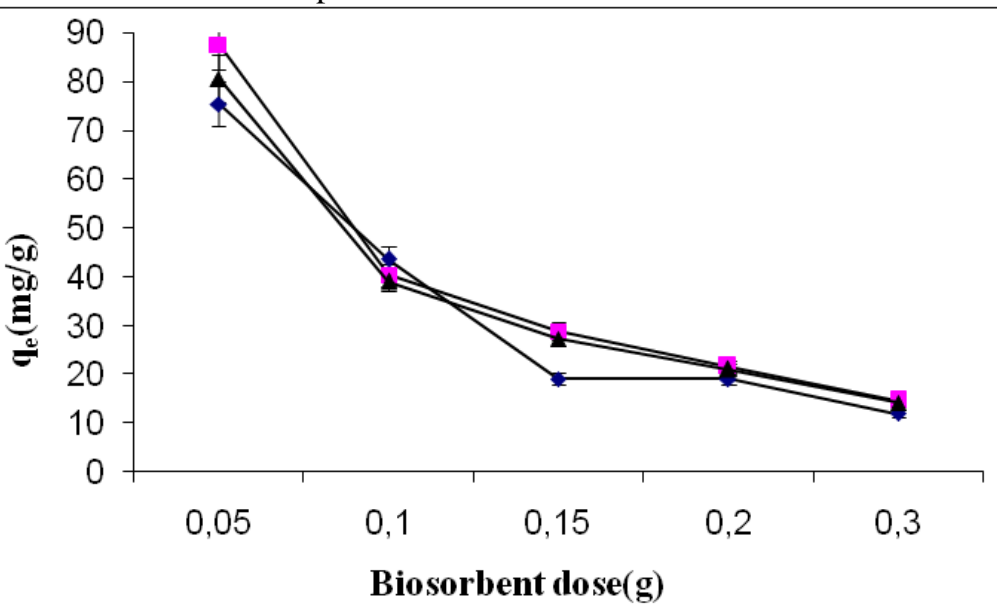

$\rightarrow-$ Native $\rightarrow$ - pretreated $\rightarrow$ immobilized

Figure 4. Effect of biosorbent dose on biosorption of Terasil Brown 2RFL using native and modified sugarcane bagasse. 


\section{Effect of initial dye concentration}

The effect of initial dye concentration (10-200 $\mathrm{mg} / \mathrm{L}$ ) on biosorption of Terasil Brown 2RFL using native, CTAB treated and immobilized sugarcane bagasse was examined using optimum $\mathrm{pH}$ and biosorbent dose, $30^{\circ} \mathrm{C}$ temperature and $120 \mathrm{rpm}$ shaking speed. The results are indicated in Fig.5. Results represented the increment in biosorption capacity of native, CTAB treated and immobilized sugarcane bagasse from 13.88 to $85.67,20.88$ to 94.65 and 10.99 to $56.77 \mathrm{mg} / \mathrm{g}$ respectively by increasing the initial Terasil Brown 2RFL concentration from 10 to $100 \mathrm{mg} / \mathrm{L}$. The $100 \mathrm{mg} / \mathrm{L}$ initial dye concentration was found to be optimum. The increasing trend might be occupation of available active binding sites of biosorbent surface with dye anions by increment in collision among them. The high concentration of disperse dye provides the driving force to decrease the hindrance of all dye anions among solid and liquid phase ${ }^{27}$. Not any significant change in biosorption capacity was observed by increasing the initial dye concentration up to $200 \mathrm{mg} / \mathrm{L}$. It might be due to saturation of all available active binding sites. Bamboo culms showed a similar effect for the removal of disperse dye ${ }^{28}$.



Figure 5. Effect of contact time on biosorption of Terasil Brown 2RFL using native and modified sugarcane bagasse.

\section{Biosorption isotherm study}

The mechanism of biosorption process can be explained by biosorption isotherms. The biosorption isotherms give the relationship between equilibrium concentration and equilibrium biosorption capacity at constant temperature. Different biosorption isotherms such as Langmuir, Freundlich, DubininRadushkevich (D-R), Temkin and Harkins Jura were applied on equilibrium data to determine the mechanism of Terasil Brown 2RFL using native, CTAB treated and immobilized sugarcane bagasse.

Langmuir isotherm explains that dye molecules adsorbed on biosorbent surface through monolayer formation which shows the homogeneous nature of biosorbent surface and absence of interaction between adsorbate molecules ${ }^{29}$. The linear form of the Langmuir isotherm is given as follows:

$$
\frac{C_{e}}{q_{e}}=\frac{1}{q_{m} b}+\frac{C_{e}}{q_{m}}
$$

Here " $\mathrm{q}_{\mathrm{e}}$ "representsthe equilibrium biosorption capacity (mg/g) while " $\mathrm{C}_{\mathrm{e}}$ " shows equilibrium concentration of dye molecules and " $\mathrm{K}_{\mathrm{a}}$ " indicates the value of biosorption constant at equilibrium that is associated to biosorption free energy while " $\mathrm{q}_{\mathrm{m}}$ " is the maximum biosorption capacity.
The linear form of Freundlich isotherm is shown in given equation:

$$
\log q_{e}=\log K_{F}+\frac{1}{n} \log C_{e}
$$

Here $\mathrm{K}_{\mathrm{F}}$ shows the value of Freundlich constant and $1 / \mathrm{n}$ represents the biosorption intensity and its value depends on heterogeneity of biosorbent surface $^{30}$.

The equilibrium data was also analyzed by applying another isotherm called DubininRadushkevich (D-R) which based on two fundamental theories. One of which is Polanyi's potential and other is Dubinin'sminipore filling theory $^{31}$.

The linear form of D-R isotherm is shown by given equation:

$$
\ln q_{e}=\ln q_{m}-\beta \varepsilon^{2}
$$

Here " $\mathrm{q}_{\mathrm{e}}$ " indicates biosorption capacity $(\mathrm{mg} / \mathrm{g})$ at equilibrium and $" \mathrm{C}_{\mathrm{e}}$ " represents the equilibrium concentration and " $\varepsilon$ " is the Polanyi potential which can be determined through following equation:

$$
\varepsilon=R T \ln \left(1+\frac{1}{C_{e}}\right)
$$

Following equation represents the linear form of Temkin isotherm $^{32}$ : 


$$
q_{e}=B \ln A+B \ln C_{e}
$$

Here $\mathrm{B}=\mathrm{RT} / \mathrm{b}, \mathrm{b}(\mathrm{kJ} / \mathrm{mol})$ shows the Temkin constant which gives the biosorption heat $(\mathrm{J} / \mathrm{mol})$ while "A"indicates the Temkin isotherm constant (L/mg).

Harkins Jura isotherm also gives information about presence of heterogeneous pores on the surface of biomass which is responsible for the production of multilayer of adsorbate molecules on biosorbent surface ${ }^{33}$. Its linear form is represented by the following equation:

$$
\frac{1}{q e^{2}}=\left(\frac{B}{A}\right)-\left(\frac{1}{A}\right) \log C e
$$

Different isotherm parameters were calculated to understand the mechanism of biosorption process by applying different isotherms and their values are shown in Table 2. It was observed that Langmuir isotherm showed best fitness on the equilibrium data obtained from the biosorption process for the removal of Terasil Brown 2RFL using native, CTAB treated and immobilized sugarcane bagasse. The well fitted model among all applied models was selected through comparison among their coefficient of correlation $\left(\mathrm{R}^{2}\right)$ values and resemblance of their calculated biosorption capacity values $\left(\mathrm{q}_{\mathrm{ecal}}\right)$ with experimental biosorption capacity values $\left(\mathrm{q}_{\text {eexp }}\right)$. The Langmuir isotherm showed high value of $R^{2}(0.99$, 0.99 and 0.98) and close resemblance between calculated biosorption capacities (82.9, 90.76 and $55.01 \mathrm{mg} / \mathrm{g}$ ) and experimental biosorption capacities $(85.7,94.65$ and $56.89 \mathrm{mg} / \mathrm{g}$ ) for the removal of Terasil Brown 2RFL with native, CTAB treated and immobilized sugarcane bagasse as compared to all other models respectively.

Table 2. Comparison of the isotherm parameters for the biosorption ofTerasil Brown 2RFL using native and

\begin{tabular}{|c|c|c|c|}
\hline \multirow[t]{2}{*}{ Isotherm models } & \multicolumn{3}{|c|}{ Terasil Brown 2RFL } \\
\hline & Native & CTAB treated & Immobilized \\
\hline \multicolumn{4}{|l|}{ Freundlich } \\
\hline $\mathrm{K}_{\mathrm{F}}\left(\mathrm{mg}^{-1(1 / \mathrm{n})} \mathrm{L}^{1 / \mathrm{n}} \mathrm{g}^{-1}\right)$ & 25.08 & 33.8 & 11.46 \\
\hline $\mathrm{n}$ & 1.77 & 0.35 & 1.24 \\
\hline $\mathrm{R}^{2}$ & 0.86 & 0.63 & 0.78 \\
\hline \multicolumn{4}{|l|}{ Langmuir } \\
\hline $\mathrm{q}_{\mathrm{m} \exp }(\mathrm{mg} / \mathrm{g})$ & 85.7 & 94.65 & 56.89 \\
\hline $\mathrm{q}_{\mathrm{m} \text { cal }}(\mathrm{mg} / \mathrm{g})$ & 82.9 & 90.76 & 55.01 \\
\hline $\mathrm{K}_{\mathrm{a}}(1 / \mathrm{mg})$ & 0.09 & 0.12 & 0.88 \\
\hline $\mathrm{R}_{\mathrm{L}}(\mathrm{L} / \mathrm{mg})$ & 0.81 & 0.92 & 0.61 \\
\hline $\mathrm{R}^{2}$ & 0.99 & 0.99 & 0.98 \\
\hline \multicolumn{4}{|c|}{ Doubinin-Radushkevich } \\
\hline $\mathrm{q}_{\mathrm{m}}(\mathrm{mg} / \mathrm{g})$ & 70.35 & 84.54 & 46.95 \\
\hline $\mathrm{K}\left(\mathrm{mol}^{2} \mathrm{~kJ}^{-2}\right)$ & -0.021 & -0.109 & -0.115 \\
\hline $\mathrm{E}\left(\mathrm{kJmol}^{-1}\right)$ & 11.14 & 9.45 & 4.34 \\
\hline $\mathrm{R}^{2}$ & 0.90 & 0.92 & 0.94 \\
\hline \multicolumn{4}{|l|}{ Temkin } \\
\hline $\mathrm{A}(\mathrm{L} / \mathrm{mg})$ & 2.41 & 1.99 & 4.85 \\
\hline $\mathrm{B}(\mathrm{J} / \mathrm{mol})$ & 34.11 & 13.66 & 19.64 \\
\hline $\mathrm{R}^{2}$ & 0.70 & 0.84 & 0.74 \\
\hline \multicolumn{4}{|l|}{ Harkins-Jura } \\
\hline A & -143.60 & -115.11 & -106.12 \\
\hline B & -1.01 & -0.21 & -1.25 \\
\hline $\mathrm{R}^{2}$ & 0.81 & 0.79 & 0.71 \\
\hline
\end{tabular}
modified sugarcane bagasse

\section{Effect of contact time}

Equilibrium time play an important role in choice of efficient biosorbent and an economical biosorption system ${ }^{34}$. The biosorption capacity of different forms of sugarcane bagasse for disperse dye was determined at different times such as 5, 10, 15, $30,45,60,90,120 \mathrm{~min}$. The effect of contact time was determined at optimum $\mathrm{pH}$ and dose, $50 \mathrm{mg} / \mathrm{L}$ 
initial Terasil Brown 2RFL concentration and $30^{\circ} \mathrm{C}$ temperature. The results depicted in Fig. 6. The results indicated that the biosorption capacity of native, CTAB treated and immobilized sugarcane bagasse for Terasil Brown 2RFL was increased from 16.98 to $78.63,28.88$ to $89.22,14.67$ to $38.99 \mathrm{mg} / \mathrm{g}$ respectively by increasing the contact time from 5 to $90 \mathrm{~min}$. The time required to attain equilibrium was found to be $90 \mathrm{~min}$. After $90 \mathrm{~min}$, there was no effect of contact time till 120 min on biosorption capacity and found it remains constant. The results showed the rapid increase of biosorption capacity at beginning of biosorption process and then slow down with passage of time and at last equilibrium was achieved. After equilibrium, there was no significant effect of time was observed. It might be due to availability of large number of vacant active binding sites for dye anions at the start of biosorption process and then biosorption process was gradually slow down with coverage of vacant sites and saturation was achieved at equilibrium. After saturation, the biosorption capacity became constant due to unavailability of binding sites ${ }^{35}$. The removal of disperse dyes from aqueous solution using low cost biosorbent like palm ash was also increased by increasing the agitation time and then found no significant effect on removal after equilibrium contact time ${ }^{36}$.

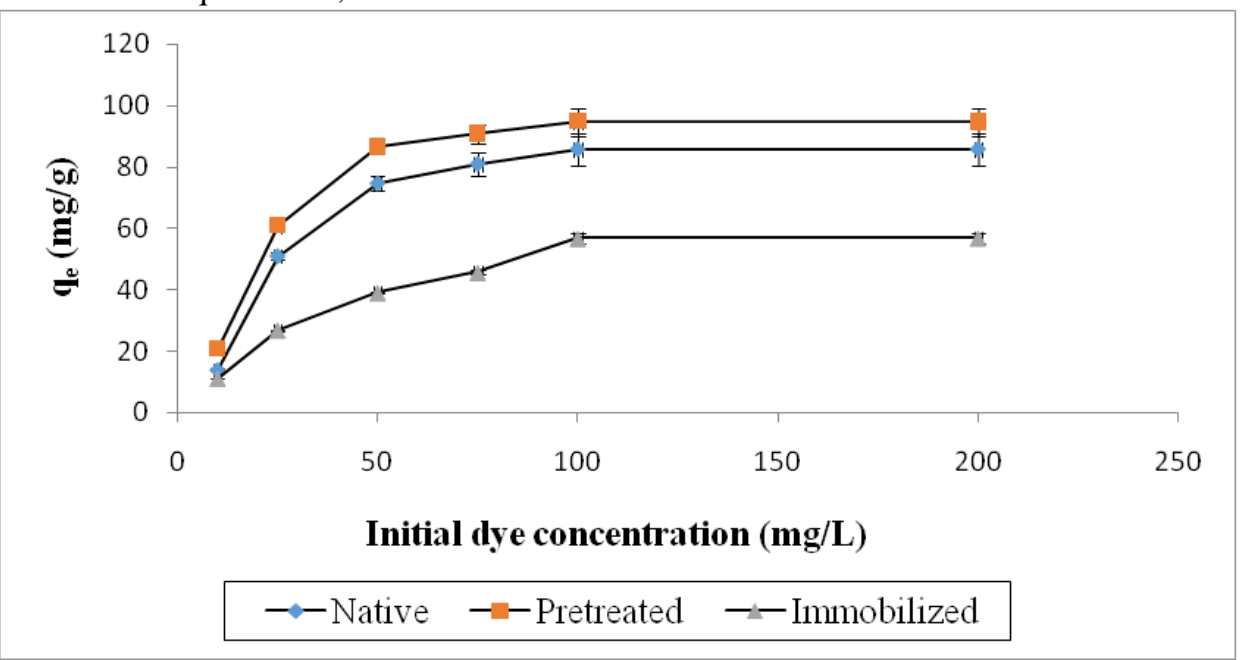

Figure 6. Effect of initial dye concentration on biosorption of Terasil Brown 2RFL using native and modified sugarcane bagasse.

\section{Kinetic study}

The rate of biosorption process for the removal of Terasil Brown 2RFL using different forms of sugarcane bagasse was determined by applying different kinetic models like pseudo-first-order, pseudo-second-order and intra particle diffusion. The linear form of pseudo- first- order is shown by the following equation ${ }^{37}$.

$$
\log \left(q_{e}-q_{t}\right)=\log q_{e}-K_{1} \cdot \frac{\mathrm{t}}{2.303}
$$

Here " $\mathrm{q}_{\mathrm{e}}$ " represents the biosorption capacity $(\mathrm{mg} / \mathrm{g})$ at equilibrium and " $\mathrm{q}_{\mathrm{t}}$ " indicates the biosorption capacity $(\mathrm{mg} / \mathrm{g})$ at any time $\mathrm{t} . " \mathrm{k}_{1}$ "is the rate constant and expressed in $\mathrm{min}^{-1}$. " $\mathrm{k}_{1}{ }^{\prime \prime}$ was calculated from the value of slope by plotting the graph $\log \left(\mathrm{q}_{\mathrm{e}}-\mathrm{q}_{\mathrm{t}}\right)$ versus $\mathrm{t}$.

The linear form of pseudo-second- order is given as follows ${ }^{38}$ :

$$
\left(\frac{t}{q_{t}}\right)=\frac{1}{K_{2} q e^{2}}+\frac{t}{q e}
$$

Here $\mathrm{k}_{2}(\mathrm{~g} / \mathrm{mg}$.min $)$ is the pseudo-second-order rate constant at equilibrium. The value of $k_{2}$ was determined from intercept of $t / q_{t}$ versus $t$ plot.
According to intra particle diffusion model, the biosorption is multistep process. Firstly, adsorbate molecules come close to biosorbent surface and then diffusion of these adsorbate molecules occur in active sites. After diffusion, some of these adsorbate molecules interact with the functional groups which exist on biosorbent surface and some diffused inside the biosorbent ${ }^{39}$.

The linear equation for intra particle diffusion model is represented as:

$$
q_{t}=k_{p i} t^{1 / 2}+C_{i}
$$

Here $" k_{p}$ " is the intra particle diffusion rate constant. Different kinetic parameters were calculated after application of all these kinetic models on kinetic data and their values are given in Table 3. The best fitted kinetic model was found to be pseudo-second-order. The decision about fitness was carried out by comparing their $\mathrm{R}^{2}$ values as well as their calculated and experimental biosorption capacity values. It was observed that the pseudosecond-order kinetic model showed high $\mathrm{R}^{2}$ values $(0.98,0.99,0.98)$ with close resemblance of $\mathrm{q}_{\text {ecal }}\left(76.88,89.12\right.$ andq $_{\text {eexp }}(78.63,89.22,38.99)$. 
Table 3. Kinetic parameters for the biosorption ofTerasil Brown 2RFL using native and modified sugarcane bagasse

\begin{tabular}{llll}
\hline Kinetic models & \multicolumn{1}{c}{ Native } & CTAB treated & Immobilized \\
\hline Pseudo first order & & & \\
$\mathrm{k}_{1}(\mathrm{l} / \mathrm{min})$ & 0.03 & 0.126 & 0.012 \\
$\mathrm{q}_{\mathrm{e}} \exp (\mathrm{mg} / \mathrm{g})$ & 78.63 & 89.22 & 38.99 \\
$\mathrm{q}_{\mathrm{e}}$ cal(mg/g) & 50.98 & 73.77 & 21.76 \\
$\mathrm{R}^{2}$ & 0.82 & 0.91 & 0.83 \\
& & & \\
Pseudo-second order & & & 0.106 \\
$\mathrm{k}_{2}(\mathrm{~g} / \mathrm{mg}$ min) & 0.123 & 0.028 & 38.99 \\
$\mathrm{q}_{\mathrm{e}} \exp (\mathrm{mg} / \mathrm{g})$ & 78.63 & 89.22 & 35.67 \\
$\mathrm{q}_{\mathrm{e}}$ cal(mg/g) & 76.88 & 89.12 & 0.98 \\
$\mathrm{R}^{2}$ & 0.98 & 0.99 & \\
& & & 1.08 \\
Intraparticle diffusion $\left._{\mathrm{k}_{\mathrm{p}}(\mathrm{mg} / \mathrm{g} \text { min }}{ }^{1 / 2}\right)$ & & & 16.09 \\
$\mathrm{C}_{\mathrm{i}}$ & 1.73 & 1.56 & 0.88 \\
$\mathrm{R}^{2}$ & 19.54 & 23.65 & \\
& 0.90 & 0.92 &
\end{tabular}

\section{Effect of temperature}

The feasibility and nature of biosorption process can be determined from thermodynamic study. For that purpose, the effect of temperature range $\left(30-60^{\circ} \mathrm{C}\right)$ on biosorption of Terasil Brown 2RFL using different forms of sugarcane bagasse (native, CTAB treated and immobilized) at $\mathrm{pH} 2,0.05 \mathrm{~g}$ biosorbent dose, $50 \mathrm{mg} / \mathrm{L}$ Terasil Brown 2RFL concentration, $30^{\circ} \mathrm{C}$ temperature and $120 \mathrm{rpm}$ shaking speed was investigated. The results are displayed in Fig.7. It was observed that efficiency of all types of sugarcane bagasse (native, CTAB treated and immobilized) for the removal of Terasil Brown 2RFL was decreased from 76.55 to $49,89.87$ to 60 , 35 to $15 \mathrm{mg} / \mathrm{g}$ by increasing the temperature from 30 to $60^{\circ} \mathrm{C}$ respectively. The reason might be the breakdown of electrostatic forces which existed between the biosorbent functional groups and adsorbate molecules at higher temperature. Due to reduction in electrostatic interaction, reduction in biosorption capacity was occurred ${ }^{40}$. The removal of Drimarine Black CL-B dye from aqueous solution has also been decreased by increasing the temperature using different forms of peanut husk ${ }^{14}$.

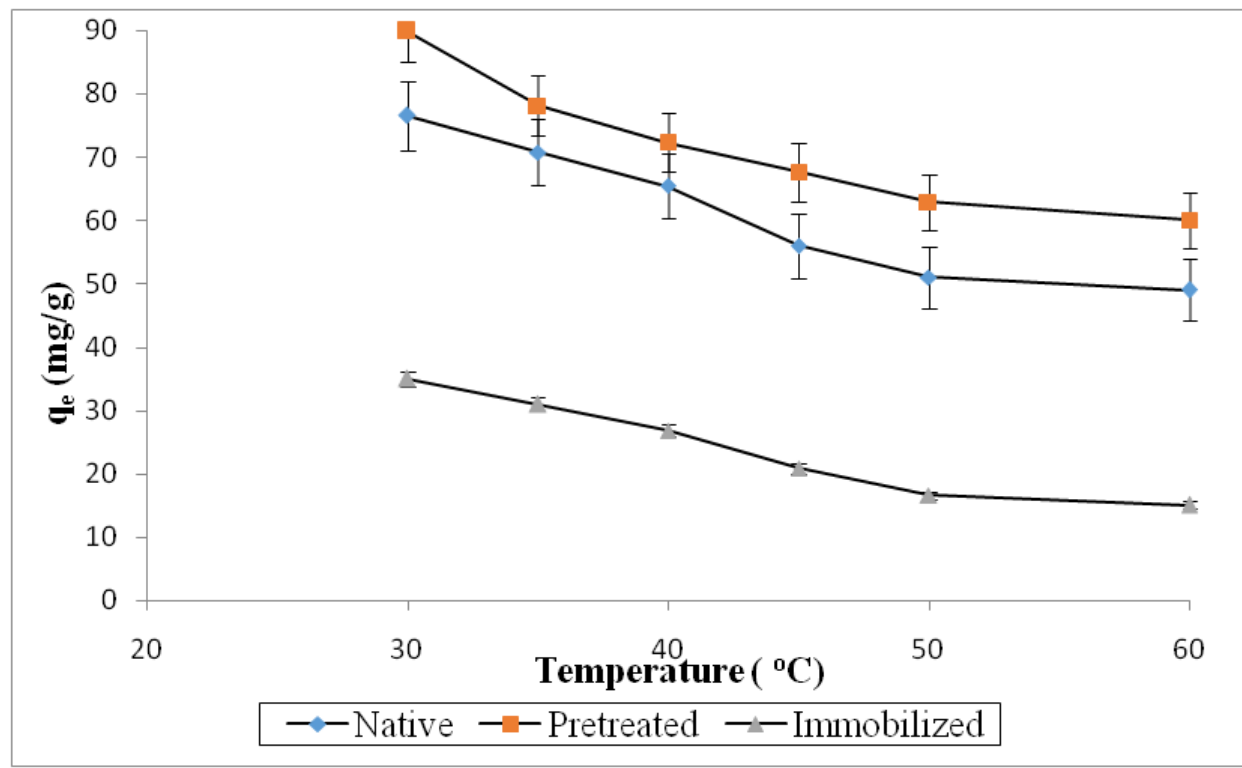

Figure 7. Effect of temperature on biosorption of Terasil Brown 2RFL using native and modified sugarcane bagasse.

Thermodynamic parameters

The nature of biosorption process for the removal of Terasil Brown 2RFL from aqueous solution using native and modified sugarcane bagasse was investigated by calculating the different thermodynamic parameters from the temperature data. These thermodynamic parameters help to understand that either the process was exothermic or endothermic in nature and also gives information about the spontaneity of biosorption process either it 
was spontaneous or non-spontaneous ${ }^{41}$. These thermodynamic parameters include Gibbs free energy change $\left(\Delta G^{0}\right)$, enthalpy change $\left(\Delta H^{\circ}\right)$ and entropy change $\left(\Delta S^{\circ}\right)$. The value of $\Delta G^{o}$ can be determined with the help of following expression:

Here, $\mathrm{K}_{\mathrm{d}}$ is the equilibrium constant and its value can be calculated through $\mathrm{K}_{\mathrm{d}}=\mathrm{q}_{\mathrm{e}} / \mathrm{C}_{\mathrm{e}}$ while $\mathrm{T}$ is the absolute temperature and $\mathrm{R}$ is the gas constant $(8.314$ $\mathrm{J} / \mathrm{mol} \mathrm{K}$ ). The $\Delta \mathrm{G}^{\mathrm{o}}$ value gives the information about spontaneity of process for the removal of Terasil Brown 2RFL using different forms of sugarcane bagasse. The positive value of $\Delta G^{o}$ showed the non-spontaneous nature of process while its negative value tells about its spontaneous nature. The negative calculated values of $\Delta G^{\circ}$ help to determined that biosorption process of Terasil Brown 2RFL was spontaneous in nature. The value of other thermodynamic parameters like $\Delta \mathrm{H}^{\mathrm{o}}$ and $\Delta \mathrm{S}^{\circ}$ can be calculated with the help of following equation.

$$
\ln \left(K_{d}\right)=\frac{\Delta \mathrm{S}^{\circ}}{R}-\frac{\Delta \mathrm{H}^{\circ}}{R} \times \frac{1}{T}
$$

The values of all thermodynamic parameters are listed in Table 4. The $\Delta \mathrm{H}^{\circ}$ and $\Delta \mathrm{S}^{\circ}$ were estimated from the slope and intercept respectively by plotting the graph between $\ln \mathrm{k}_{\mathrm{d}}$ and $1 / \mathrm{T}$. The negative value of $\Delta \mathrm{H}^{\mathrm{o}}$ investigated that the biosorption of this disperse dye using native and modified sugarcane bagasse was exothermic in nature while the positive value of $\Delta S^{\circ}$ showed the usefulness of reaction. Similar effect of temperature on the removal of dyes has also been reported by other researchers ${ }^{42}$.

Table 4. Thermodynamic parameters for the biosorption of Terasil Brown 2RFL using native and modified sugarcane bagasse

\begin{tabular}{|c|c|c|c|}
\hline \multirow{3}{*}{$\begin{array}{l}\text { Temp } \\
\text { (K) }\end{array}$} & \multicolumn{3}{|c|}{ Terasil Brown 2RFL } \\
\hline & Native & CTAB treated & Immobilized \\
\hline & $\Delta G^{0}-\Delta H^{0} \Delta S^{0}$ & $-\Delta G^{0} \quad-\Delta H^{0} \Delta S^{0}$ & $\Delta G^{0}-\Delta H^{0} \Delta S^{0}$ \\
\hline 303 & $-1.98,13.66,1.82$ & $-2.16,19.38,0.098$ & $-2.71,25.79,0.248$ \\
\hline 308 & -0.72 & -0.81 & -1.9 \\
\hline 313 & 0.56 & 0.412 & -1.2 \\
\hline 318 & 1.12 & 0.810 & 0.96 \\
\hline 323 & 1.56 & 1.1 & 1.14 \\
\hline 333 & 2.4 & 2.05 & 1.66 \\
\hline
\end{tabular}

${ }^{*} \Delta \mathrm{G}^{\mathrm{o}}(\mathrm{kJ} / \mathrm{mole}),{ }^{*} \Delta \mathrm{H}^{\mathrm{o}}(\mathrm{kJ} / \mathrm{mole}),{ }^{*} \Delta \mathrm{S}^{\mathrm{o}}(\mathrm{kJ} / \mathrm{mol} \mathrm{K})$

\section{Effect of salt and heavy metal ions}

The wastewater which discharged from different industries contained the some quantity of salt and heavy metal ions in $i^{43}$. For making this process more applicable on industrial scale, the effect of different concentration of salt and heavy metal ions was checked on the efficiency of sugarcane bagasse for the removal of Terasil Brown 2RFL from wastewater. The effect of $\mathrm{NaCl}(0.2$ to $1 \%)$ and $\mathrm{pb}^{2+}$ ions $(0.2$ to $1 \%)$ was investigated at constant $\mathrm{pH}$ 2, $50 \mathrm{ppm}$ initial dye concentration, $30^{\circ} \mathrm{C}$ temperature and $120 \mathrm{rpm}$ shaking speed. It was observed that the efficiency of sugarcane bagasse for the removal of Terasil Brown 2RFL was reduced from 58.78 to $23.65 \mathrm{mg} / \mathrm{g}$ by increasing the concentration of salt from 0.2 to $1 \mathrm{M}$. The reason might be the creation of hindrance in the path of anions for reaching biosorbent surface due to salt ions ${ }^{44}$. The increment in removal of Terasil Brown 2RFL was observed by increasing the concentration of $\mathrm{pb}^{2+}$ ions from 0.2 to $1 \%$. The biosorption capacity was increased from 65.55 to $80.76 \mathrm{mg} / \mathrm{g}$ by increasing $\mathrm{pb}^{2+}$ ions concentration from 0.2 to $1 \%$. The reason behind such behavior might be the formation of complex between dye anions and $\mathrm{pb}^{2+}$ ions which showed better attachment on biosorbent surface than dye anions ${ }^{45}$.

\section{Desorption study}

Desorption study plays an important role in the selection of an efficient and economical biosorbent for biosorption process. This study also helps to make the biosorption process more ecofriendly and cost effective. The desorption depends upon the $\mathrm{pH}$ of the eluent which is used for this purpose. Therefore, the selection of eluent is very critical $^{46}$. The desorption of Terasil Brown 2RFL from sugarcane bagasse was carried out by using the different concentrations of $\mathrm{NaOH}(0.2$ to $1 \mathrm{M})$ because the lower $\mathrm{pH}$ was effective for biosorption. The results showed that the \% desorption was increased from 40.87 to $80.67 \%$ by increasing the concentration from 0.2 to $0.8 \mathrm{M}$ and then found not any significant effect. The reason might be the deprotonation of functional groups which existed on surface of biosorbent which caused reduction in electrostatic interaction between dye anions and functional groups. Maximum desorption $(80 \%)$ was obtained by using $0.8 \mathrm{M}$ of $\mathrm{NaOH}$. The results are given in Fig.10. Same behavior was observed in 
desorption of Remazol Brilliant Blue $\mathrm{R}$ from Jatropha curcas pods using $\mathrm{NaOH}^{47}$.

\section{FTIR analysis}

The FTIR analysis was done for the identification of biosorbent active functional groups which were responsible for the biosorption of Terasil Brown 2RFL from aqueous solution in the range of $400-4000 \mathrm{~cm}^{-1}$. The FTIR spectra of native and dye loaded sugarcane bagasse are represented in Fig.8 (a $\&$ b). Sugarcane bagasse is usually made of cellulose, hemicelluloses and lignin which contain different functional groups such as ester, aldehyde, carboxylic acid, ketone, alcohol and alkenes in their composition. The presence of $-\mathrm{OH}$ group was confirmed by the presence of peak at 3400 and 3333 $\mathrm{cm}^{-1}$ in native and dye loaded sugarcane bagasse respectively. The lower intensity and broadening of $-\mathrm{OH}$ peak in dye loaded biomass showed the involvement of this functional group in the removal of Terasil Brown 2RFL from aqueous solution. The appearance of peak at 2918.37 and $2900 \mathrm{~cm}^{-1}$ in both native and dye loaded biomass indicated the existence of $\mathrm{C}-\mathrm{H}$ stretching and confirmed the presence of $-\mathrm{CH}$ and $\mathrm{CH}$ groups in the sugarcane bagasse composition. The lower intensity of these bands showed their interaction with the functional groups present in dye which is responsible for dye removal. The allocation of band at 1600.15 and $1750 \mathrm{~cm}^{-1}$ due to $\mathrm{C}=\mathrm{O}$ stretching showed the participation of this functional group in biosorption process. The peaks which obtained at 1038.48 and $1032.48 \mathrm{~cm}^{-1}$ indicated the involvement of $\mathrm{C}-\mathrm{O}$ stretching vibration of carboxylic acids and alcohols.

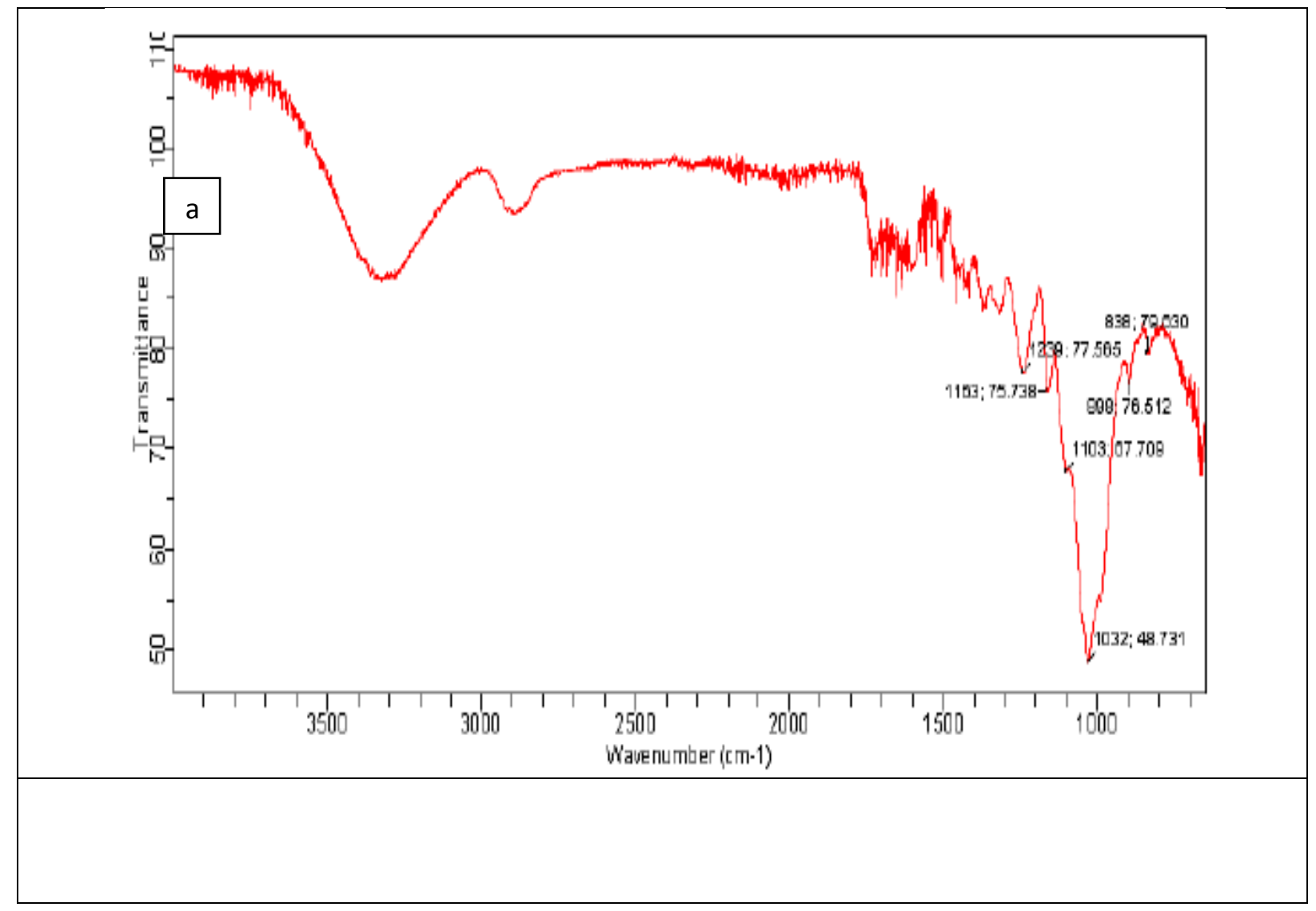




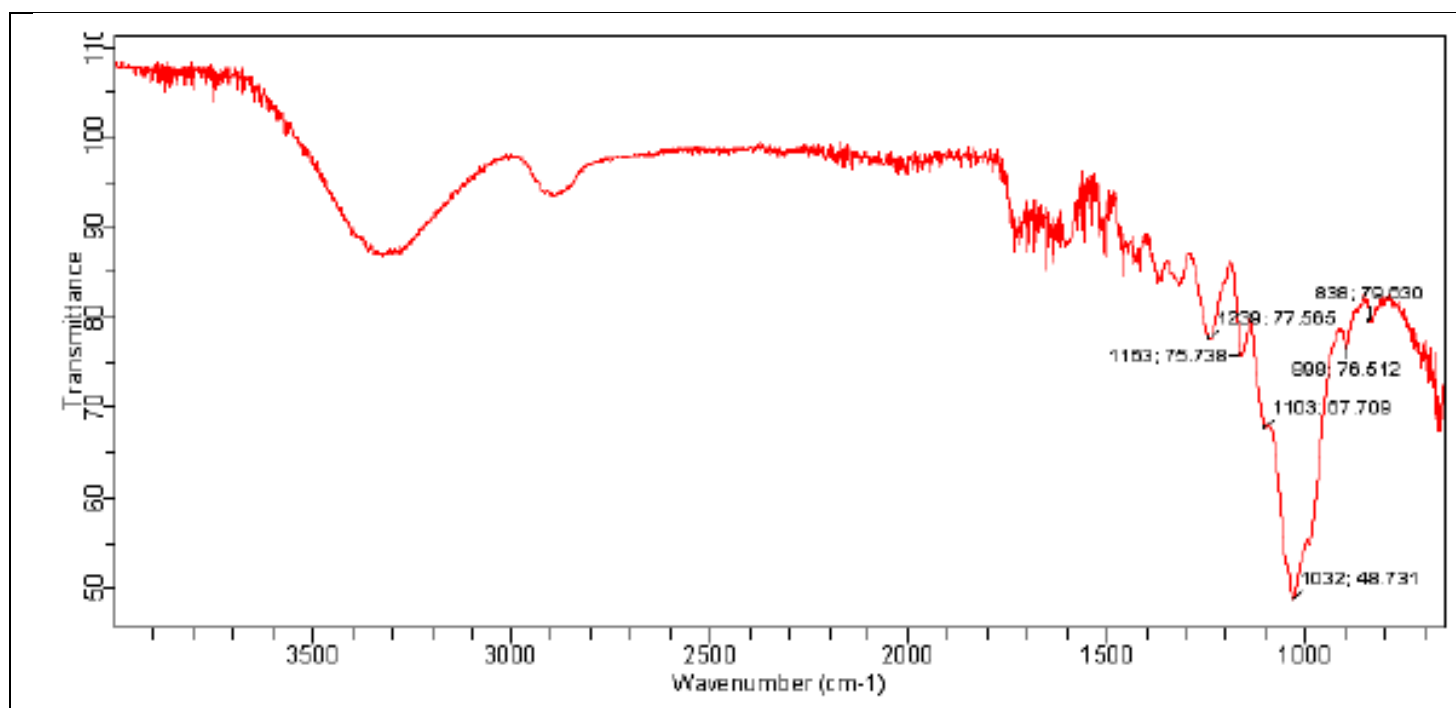

Figure 8. FTIR spectra of (a) native (b) dye loaded sugarcane bagasse

\section{Conclusion}

Biosorbents have potential to remove the dyes from wastewater due to presence of different functional groups on their surface which made them efficient and highly selective. In present study, the efficiency of cost effective sugarcane bagasse in native and modified forms has been checked for removal of Terasil Brown 2RFL from aqueous solution in batch mode using the biosorption technology. This technique observed as highly efficient promising alternative to conventional treatment systems. Biosorption technology is not only economical but also simple in design and easy to handle. It was observed that the CTAB treated sugarcane bagasse showed the good biosorption capacity for this dye at optimized conditions than other forms. Langmuir and pseudo-second-order showed the best fitness on equilibrium and kinetic experimental data respectively. From thermodynamic parameters, it was observed that the biosorption process was exothermic and spontaneous in nature. The involvement of different functional groups like alcohol, carboxylic acid, aldehyde and ketone was observed for the biosorption of Terasil Brown 2RFL with the help of Fourier transform infrared spectroscopy. The showed that bagasse could be used as low cost material for the treatment of dyes containing wastewaters.

\section{References}

1- A. Mittal, J. Mittal, A. Malviya, V.K. Gupta. J. Colloid Interface Sci., 2009, 340, 16-26.

2- V.K. Gupta, S. Agarwal, T.A. Saleh. J. Hazard. Mater., 2011, 185, 17-23.

3- V.K. Gupta, I. Ali, T.A. Saleh, A. Nayak, S. Agarwal. RSC Adv., 2012, 2, 6380-6388.
4- V. Gupta, T. Saleh. Environ Sci Pollut Res., 2013, 20, 2828-2843.

5- V.K. Gupta, S. Agarwal, T.A. Saleh. J. Hazard. Mater., 2011, 185, 17-23.

6- V.K. Gupta, S. Agarwal, T.A. Saleh. Water Res., 2011, 45, 2207-2212.

7- V.K. Gupta, R. Kumar, A. Nayak, T.A. Saleh, M.A. Barakat., 2013, 193, 24-34.

8- A.K. Jain, V.K. Gupta, A. Bhatnagar, Suhas. Sep. Sci. Technol., 2003, 38, 463-481.

9- S. Karthikeyan, V.K. Gupta, R. Boopathy, A. Titus, G. Sekaran, J. of Mol. Liq., 2012, 173, 153-163.

10- H. Khani, M.K. Rofouei, P. Arab, V.K. Gupta, Z. Vafaei. J. Hazard. Mater., 2010, 183, 402-409.

11- A. Mittal, D. Kaur, A. Malviya, J. Mittal, V.K. Gupta. J. Colloid Interface Sci., 2009, 337, 345-354.

12- T.A. Saleh, V.K. Gupta. J. Colloid Interface Sci., 2012, 371, 101-106.

13- A. Mittal, J. Mittal, A. Malviya, V.K. Gupta. J. Colloid Interface Sci., 2010, 344, 497-507.

14- A. Mittal, J. Mittal, A. Malviya, D. Kaur, V.K. Gupta. J. Colloid Interface Sci., 2010, 342, 518-527.

15- S. Noreen, H.N. Bhatti. J Ind Eng Chem., 2014, 20, 1684-1692.

16- Y. Hamzeh, A. Ashori, E. Azadeh, A. Abdulkhani. Mater. Sci. Eng C., 2012, 32, 1394-1400.

17- S. Karcher, A. Kornmüller, M. Jekel. Dyes Pigm., 2001, 51, 111-125.

18- H. Yazıcı, M. Kılıç, M. Solak. J. Hazard. Mater.,2008, 151, 669-675.

19- J. Mao, S.W. Won, K. Vijayaraghavan, Y.-S. Yun. Bioresour. Technol.,2009, 100, 1463-1466. 
20- H.N. Bhatti, R. Khalid, M.A. Hanif. Chem. Eng. J.,2009, 148, 434-443.

21- W. Jianlong. Process Biochem.,2002, 37, 847-850.

22- D. Zhou, L. Zhang, S. Guo. Water Res.,2005, 39, 3755-3762.

23- Q.L. Qin-Yan Yue, Bao-Yu Gao, Yan Wang. Sep. Purif. Technol.,2007, 54 279-290.

24- S. Zhao, F. Zhou, L. Li, M. Cao, D. Zuo, H. Liu. Compos. Part B: Eng.,2012 , 43, 1570-1578.

25- K.R. Raj, A. Kardam, J.K. Arora, S. Srivastava, M.M. Srivastava. Clean Technol. Environ. Pol., 2012, 1-8.

26- H.N.B. S. Zaheer, S. Sadaf, Y. Safa and M. Zia-ur-Rehman. J. Ani. Plan. Sci.,2014, 24, 272-279.

27- M.T. Yagub, T.K. Sen, S. Afroze, H.M. Ang. Adv. Col. Inter. Sci.,2014,209, 172-184.

28- L. Wang. J. Environ. Manage., 2012,102, 79-87.

29- I. Langmuir. J. Am. Chem. Soc.,1917, 39, 1848-1906.

30- H.M.F. Freundlich. J. Phys.Chem.,1906,57, 385-470.

31- L.V.R. M.M. Doubinin. Chem. Zentr., 1947, 1, 875.

32- V.P. M.J. Temkin. Acta. Physiochim., 1940, 12,217-222.

33- S. Rangabhashiyam, N. Anu, M.S. Giri Nandagopal, N. Selvaraju. J. Environ. Chem. Eng., 2014, 2, 398-414.
34- N. Rabiei, M.H. Kish, S.H. Amirshahi, M. Radjabian. Dyes Pigm.,2012, 94, 386-392.

35- J.S. Piccin, C.S. Gomes, L.A. Feris, M. Gutterres. Chem. Eng. J.,2012, 183, 30-38.

36- L.S.L. M. H. Isa , F. A.H. Asaari , H. A. Aziz , N. A. Ramli , J. P. A. Dhas. Dyes Pigm.,2012, 74, 446- 453.

37- S. Lagergren. Handlingar, 1898,24, 1-39.

38- G.M. Y.S. Ho, D.A.J. Wase, C.F. Foster. Adsorp. Sci. Technol.,2000, 18, 639-650.

39- W.J. Weber, J.C. Morris.J. San. Eng. Div., 1963, 89, 31-59.

40- H. Ucun.Sci. Res. Ess., 2011, 6, 4113-4124.

41- P.D. Saha, S. Chakraborty, S. Chowdhury. Coll. Surf. B: Bioint.,2012, 92, 262-270.

42- A. Roy, B. Adhikari, S.B. Majumder. Ind. Eng. Chem. Res.,2013, 52, 6502-6512.

43- Y.S. Al-Degs, M.I. El-Barghouthi, A.H. El-Sheikh, G.M. Walker. Dyes Pigm., 2008,77, 16-23.

44- J. Gao, Q. Zhang, K. Su, R. Chen, Y. Peng. J. Hazard. Mater.,2010,174, 215-225.

45- Z. Aksu, S. Ertuğrul, G. Dönmez. J. Hazard. Mater., 2009,168, 310-318.

46- G.Z. Kyzas, N.K. Lazaridis, A.C. Mitropoulos. Chem. Eng. J., 2012, 148-159.

47- P. Sathishkumar, M. Arulkumar, T. Palvannan. J. Clean. Prod.,2012, 22, 67-75. 